\title{
Measurement of Quantitative Colour Values of Ore Minerals Using a Filter-Photocell Method
}

\author{
Hiyam A. Mohammad \\ Department of Geology \\ College of Science \\ Mosul University
}

\author{
Allan J. Hall \\ Department of Archaeology \\ University of Glasgow \\ $U . K$
}

(Received 23/5/2011, Accepted 17/7/2011)

\begin{abstract}
This study describes and discusses the feasibility of the development of an inexpensive filter- photocell system suitable for quantitative colour measurement of ore minerals under the reflected-light microscope. In this study, reflectance measurements of eight minerals were obtained using broad band coloured filters with spectral transmissions approximating to those theoretically required. Using this method, only three measurements of the intensity of reflectance for each mineral and the standard ( $\mathrm{SiC}$ ) were taken using red, green and blue (RGB) filters.

Colour values obtained in this study are compared with IMA/COM reference values and are satisfactory to within $\pm 1 \%$. Also, the obtained colour values revealed that it might be possible to apply this simple, rapid and direct method in studies where low-cost instrumentation is required, especially in the teaching of ore mineral identification and quantitative colour theory. It is worth mentioning that although the results of this study are promising, conventional spectral reflectance measurements $(380-740 \mathrm{~nm})$ will remain the best recommended method for obtaining the most accurate colour values.
\end{abstract}

Keywords: reflectance measurement, quantitative colour values, image analysis, reflected light microscope.

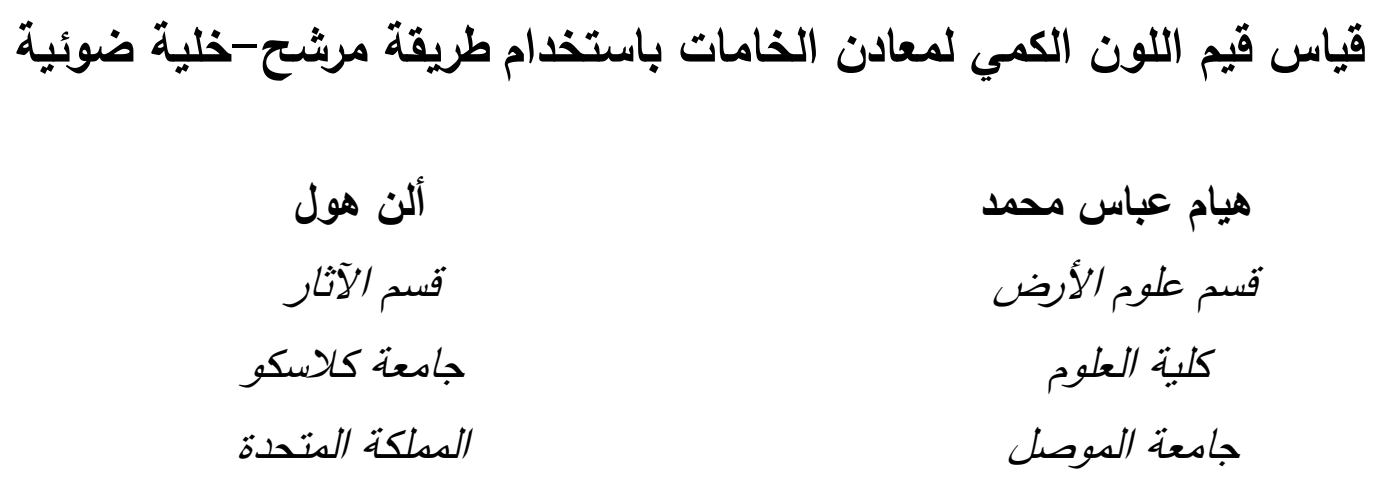




\begin{abstract}
الملخص
يتناول البحث الحالي وصف ومناقثة إمكانية تطوير نظام مرشح- خلية ضوئية غير باهض الثن وملأيم لقياس اللون الكمي لمعادن الخامات تحت المجهر العاكس للضوء.تم الحصول على قياس قيم الانعكاسية لثمانية معادن معتمة باستخدام مرشحات ملونة عريضة الحزمة وذات نفاذ طيفي مقارب للمطلوب. باستخدام هذه الطريقة تم أخذ ثناث قياسات فقط لشدة الانعكاسية لكل من المعدن والنموذج المعياري (SiC) باستخدام مرشحات ذات لون أزرق، أخضر وأحمر •

قورنت القيم اللونية المستحصلة من هذه الدراسة مع القيم المرجعية وقد تم اعتبار النتائج التي تمنلك فرق تطابق مقارب 土1\% قيم مقنعة. كما أظهرت نتائج الدراسة إمكانية تطبيق هذه الطريقة البسيطة والسريعة المباشرة في الدراسات التي تتطلب أجهزة رخيصة كما هو الحال في مختبرات تدريس تشخيص معادن الخام ونظرية اللون الكمي. من الجدير بالإشارة انه بالرغم من أن النتائج الحالية تبدو واعدة إلا أن طريقة قياس انعكاس الطيف التقليدية (380-740 nm) تبقى هي الأفضل للحصول على أدق القيم اللونية. الكلمات الدالة: قياس الأنعكاسية، قيم اللون الكمي، التحليل الصوري، مجهر الضوء العاكس.
\end{abstract}

\title{
INTRODUCTION
}

Recent work on multispectral image analysis (Gomes et al., 2010; Kruse, 1996; Pirard and Lebichot, 2011; Pirard et al., 2007; Pirard et al., 2008 and Shippert, 2008) using expensive and very sophisticated apparatus confirm its usefulness in examining mineral paragenesis in ores, but the use of conventional spectroscopic databases such as the Quantitative Data File (QDF) are still recommended and were considered by Pirard (2004) to remain the most reasonable method for mineral identification. Keeping this in mind, the authors think that there is a need for a simple low-cost method of measuring colour values for routine optical examination in teaching laboratories. These reasons encouraged the authors to carry out this work. In order to cover the concept and relation between the two methods, a brief outline of conventional spectral reflectance and multispectral image analysis is represented in this introductory. Quantitative colour theory applied to ore minerals has led to a better understanding and description of the colour of opaque minerals under the reflected light microscope. Quantitative colour values are available for many ore minerals (Criddle, 1980; Criddle and Stanley, 1993; Henry, 1977 and Uytenbogaardt and Burke 1971). These quantitative colour values have been used as significantly reliable determinative criteria in many opaque minerals identification schemes. All these schemes made use of the principles of the CIE (1931) colour system. In the 1960s and 1970s, this approach received great attention as a result of the development of a photo-multiplier apparatus suitable for reflectance measurements (Cervelle et al., 1971 and Piller, 1966).

The Bowie-Simpson system (1978) used reflectance in monochromatic light at four wavelengths across the visible spectrum. This was followed by the original 
NISOMI system (Nottingham Interactive System for Opaque Mineral Identification) represented by Atkin and Harvey (1979a) that used reflectance at four wavelengths, chromaticity and VHN (Vickers Hardness Number) as its discriminating parameters. This work was later improved by Atkin and Harvey (1979b) who developed an identification scheme that operated on a desk-top computer and utilized the quantitative colour values $\left(\mathrm{x}, \mathrm{y}, \mathrm{Y} \%, \mathrm{P}_{\mathrm{e}} \%\right.$ and $\left.\lambda_{\mathrm{d}}\right)$.

Criddle (1998) in a textbook on ore mineralogy pointed out the potential of considering image analysis based on optical properties. This becomes feasible using the recently discussed efforts made to quantify reflectance data using multispectral imaging of ore minerals under the reflected light microscope (Pirard, 2004). This involves using a digital video camera equipped with a filter wheel with selection of narrow bandwidth $(10 \mathrm{~nm})$ interference filters and is quantitatively compared to colour imaging using tristimulus red, green and blue filters in triple-CCD video camera in reflected light microscopy (see Pirard et al., 1999 for more details). He concluded that the results he obtained using multispectral imaging are close enough to the spectral resolution of the Quantitative Data File (Criddle and Stanley, 1993). Pirard (2004) discussed an automatic identification scheme using multivariant image with cost-effective sensors similar to those used in remote sensing. This requires special modifications to the classical design of the ore microscope to accommodate this scientific video camera.

It is obvious from the preceding introduction that quantitative colour values are available for most ore minerals and there are a variety of identification schemes. But most of the previously discussed measurement schemes need expensive and/or complicated apparatus. Thus the goal of this work is to present a simple method of obtaining colour values using low-cost instrumentation. This is especially needed in teaching laboratories involved with ore mineral identification in polished section and in the teaching of quantitative colour theory.

The filter-photocell method, although not new (Judd and Wyszecki, 1963), appears to be little known by ore microscopists so we feel that presentation of our preliminary results is warranted at this stage in order to kindle interest in further assessment and development. The method is relatively simple, is based on sound theoretical principles and involves only three reflectance measurements using blue, green and red filters. The method is described below after a brief outline of the necessary quantitative colour theory. The Commission on Ore Microscopy of the International Mineralogical Association (COM) has issued a recommendation on terminology (Henry, 1980) and this is adopted below resulting in slight modifications to terms and symbols taken from earlier publications.

\section{The CIE (1931) Colour System (Conventional):}


The system of colour measurement used in ore microscopy is that of the International Commission on Illumination usually known as the CIE (Commission Internationale d'Eclairage); the use of the CIE (1931) System has been explained in detail by Hardy (1936) and summarized by Gribble and Hall, 1992.

Any colour, including spectral colours, can be duplicated by adding, or for certain colours subtracting, the light from three primary sources (red, green and blue) in the proper proportions; the amounts of each of the primaries required are called the tristimulus values $\mathrm{X}, \mathrm{Y}$ and $\mathrm{Z}$. The red, green and blue primaries adopted by the CIE are not real colours but transformed primaries which have the advantage that the three tristimulus values are positive for all real colours. The spectral curves of the tristimulus values required in the matching of the spectral colours are shown in Figure 1. The tristimulus values of a colour of an ore mineral under the reflected-light microscope depend on the energy distribution of the illuminant $(\mathrm{E})$, the spectral reflectance curve of the mineral and the spectral curves of the tristimulus values of the spectral colours (X,Y and Z in Fig.1). In the weighted ordinate method of calculation, the visible spectrum (380-740 $\mathrm{nm}$ ) is divided into a suitable number of equal wavelength intervals (18 spots at $20 \mathrm{~nm}$ interval, see Fig. 2). The contribution to the stimulation made by the light for each interval is determined from the functions $\mathrm{E}^{\bar{x}} \mathrm{R}$, $\mathrm{E} \bar{y} \mathrm{R}$ and $\mathrm{E}^{\bar{z}} \mathrm{R}$ using the standard tabulated data in Hardy (1936) and the reflectance values of the mineral. The results are simply added up to give three summations which correspond to the three tristimulus values.

Thus for the C-source (daylight):

$$
\begin{aligned}
& X=\sum_{380}^{740} E_{\mathrm{C}} \bar{X} R \\
& Y=\sum_{380}^{740} E_{\mathrm{C}} \bar{Y} R \\
& Z=\sum_{380}^{740} E_{\mathrm{c}} \bar{Z} R
\end{aligned}
$$

Therefore the only new data required to calculate the tristimulus values of a mineral is the spectral reflectance curve which is independent of the source illuminant. It is noteworthy that the three tristimulus values can be determined independently of each other.

The tristimulus values are not very meaningful in terms of colour perception but they can be converted to the three Helmholtz colour values which do have a simple meaning in colour terminology. The three values are the dominant wavelength $\left(\lambda_{d}\right)$, the purity $\left(\rho_{\mathrm{e}}\right)$ and the luminance $(\mathrm{Y} \%)$. These correspond in alternative terminology 
to hue (or tint); saturation; and brightness, respectively. The Y luminance value is obtained from:

$$
Y \%=Y \times 100 /\left(\sum_{380}^{740} E_{\mathrm{c}} \overline{\mathbf{Y}}\right)
$$

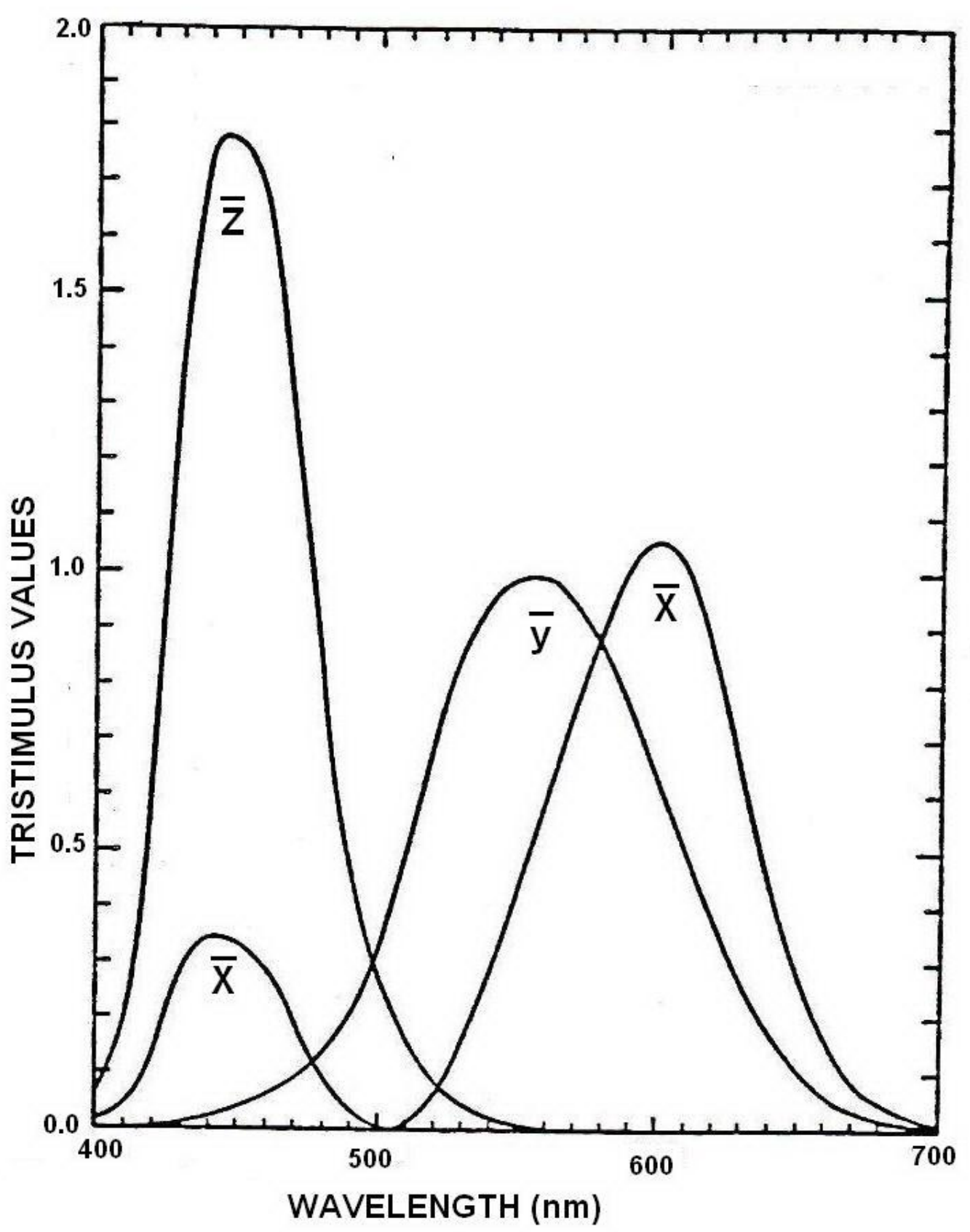

Fig.1: Spectral Curves of the Tristimulus Values of the Spectrum Colours. These Curves form the Basis of the CIE (1931) Colour System and Correspond to the Spectral Sensitivity of the CIE Standard Eye. $\mathrm{CIE}=$ is Commission Internationale d'Eclairage. 


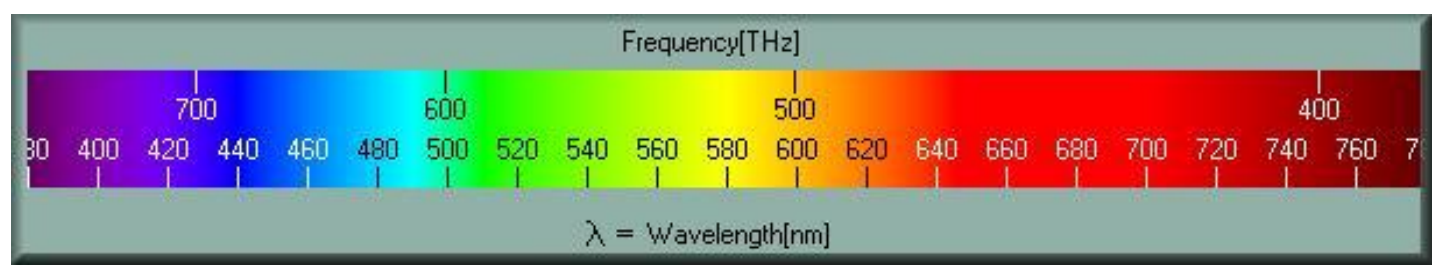

(A)

\begin{tabular}{|c|c|c|c|c|c|c|c|c|c|}
\hline \multicolumn{10}{|c|}{ Wavelength vs RGB Values } \\
\hline $\begin{array}{l}\text { Wave } \\
\text { Length }\end{array}$ & Red & Green & Blue & Color.BMP & $\begin{array}{c}\text { Wave } \\
\text { Length }\end{array}$ & Red & Green & Blue & Color.BMP \\
\hline 400 & 131 & 0 & 181 & & 560 & 195 & 255 & 0 & \\
\hline 410 & 126 & 0 & 219 & & 570 & 225 & 255 & 0 & \\
\hline 420 & 106 & 0 & 255 & & 580 & 255 & 255 & 0 & \\
\hline 430 & 61 & 0 & 255 & & 590 & 255 & 223 & 0 & \\
\hline 440 & 0 & 0 & 255 & & 600 & 255 & 190 & 0 & \\
\hline 450 & 0 & 70 & 255 & & 610 & 255 & 155 & 0 & \\
\hline 460 & 0 & 123 & 255 & & 620 & 255 & 119 & 0 & \\
\hline 470 & 0 & 169 & 255 & & 630 & 255 & 79 & 0 & \\
\hline 480 & 0 & 213 & 255 & & 640 & 255 & 33 & 0 & \\
\hline 490 & 0 & 255 & 255 & & 650 & 255 & 0 & 0 & \\
\hline 500 & 0 & 255 & 135 & & 660 & 255 & 0 & 0 & \\
\hline 510 & 0 & 255 & 0 & & 670 & 255 & 0 & 0 & \\
\hline 520 & 54 & 255 & 0 & & 680 & 255 & 0 & 0 & \\
\hline 530 & 94 & 255 & 0 & & 690 & 255 & 0 & 0 & \\
\hline 540 & 129 & 255 & 0 & & 700 & 255 & 0 & 0 & \\
\hline 550 & 163 & 255 & 0 & & & & & & \\
\hline
\end{tabular}

(B)

Fig. 2: (A)Wavelengths and their Corresponding Colours of the Visible light Spectrum.

(B) Table of Wavelength Values Versus \% Reflectivity at that Wavelength (example). Taken from John Betts-Fine Mineral (Webmineral.Com).

The green primary of the CIE system was chosen so that the spectral curve of the $\mathrm{Y}$ tristimulus values required in the matching of the spectral colours ( $\mathrm{Y}$ in Fig. 1) would correspond exactly to the spectral sensitivity of the normal eye. Because the eye is so sensitive to green light the $\mathrm{Y}$ luminance value can be used as a measure of the relative brightness on the scale $0 \%$ (black) to $100 \%$ (perfect white) of a mineral seen in polished section using a white light illuminant.

The dominant wavelength and purity can be obtained by plotting the trichromatic (or chromaticity) coordinates of the colour on the CIE (1931) 
chromaticity diagram (Fig. 3). The two chromaticity coordinates (x and y) required for plotting the colour on the diagram are obtained from the formulae:

$$
\mathrm{x}=\frac{X}{X+Y+Z} \quad \text { and } \quad \mathrm{y}=\frac{Y}{X+Y+Z}
$$

\section{METHOD OF WORK}

\section{The filter-photocell method (this study) :}

The filter-photocell method is based on the concept of using a photometer system modified by filters so that the three measurements are taken under conditions corresponding to the spectral sensitivity of the CIE (1931) standard eye (see Fig.4). This provides a rapid and more direct means of determining the tristimulus values than using the spectral reflectance curves. A simplified diagram of the necessary apparatus used in this study is presented in Figure 5. In our prototype, the sensitive photomultiplier on the Vickers M74 microphotometer, at Applied Geology/University of Strathclyde, was used with three (green, blue and red) broad band coloured filters instead of monochromatic filters. The coloured filters used were characterized by spectral transmissions approximating to these theoretically required. Ultraviolet, infra-red and neutral density filters were used to protect the sensitive photomultiplier. A SiC standard $(\mathrm{x}=0.307, \mathrm{y}=0.313$ and $\mathrm{Y}=20.35)$ was used as the reference polished section with a Lanham specimen interchanging stage. Micro-reflectance measurements were taken in the usual way (Galopin and Henry 1972) using linearly polarized light and field and measurement stops.

Reflectance measurements, using the filter method, were carried out on eight polished sections of opaque minerals (oxides and sulfides). A selection of spots on each mineral were measured in order to minimize errors that can arise from many fundamental error sources, such as specimen preparation or optical aberration. These error sources and their avoidance have been discussed in detail by Bowie and Henry (1964), Leow (1966), Piller (1966 and 1977), and Galopin and Henry (1972). Therefore, in this study, the authors always emphasized the importance of taking the measurements in areas with homogeneous surfaces where no tarnishing had taken place, and which were devoid of inclusion, scratches, pits or zonation. Also, the areas were not too close to a grain boundary where optical mixing of spectra might occur. 


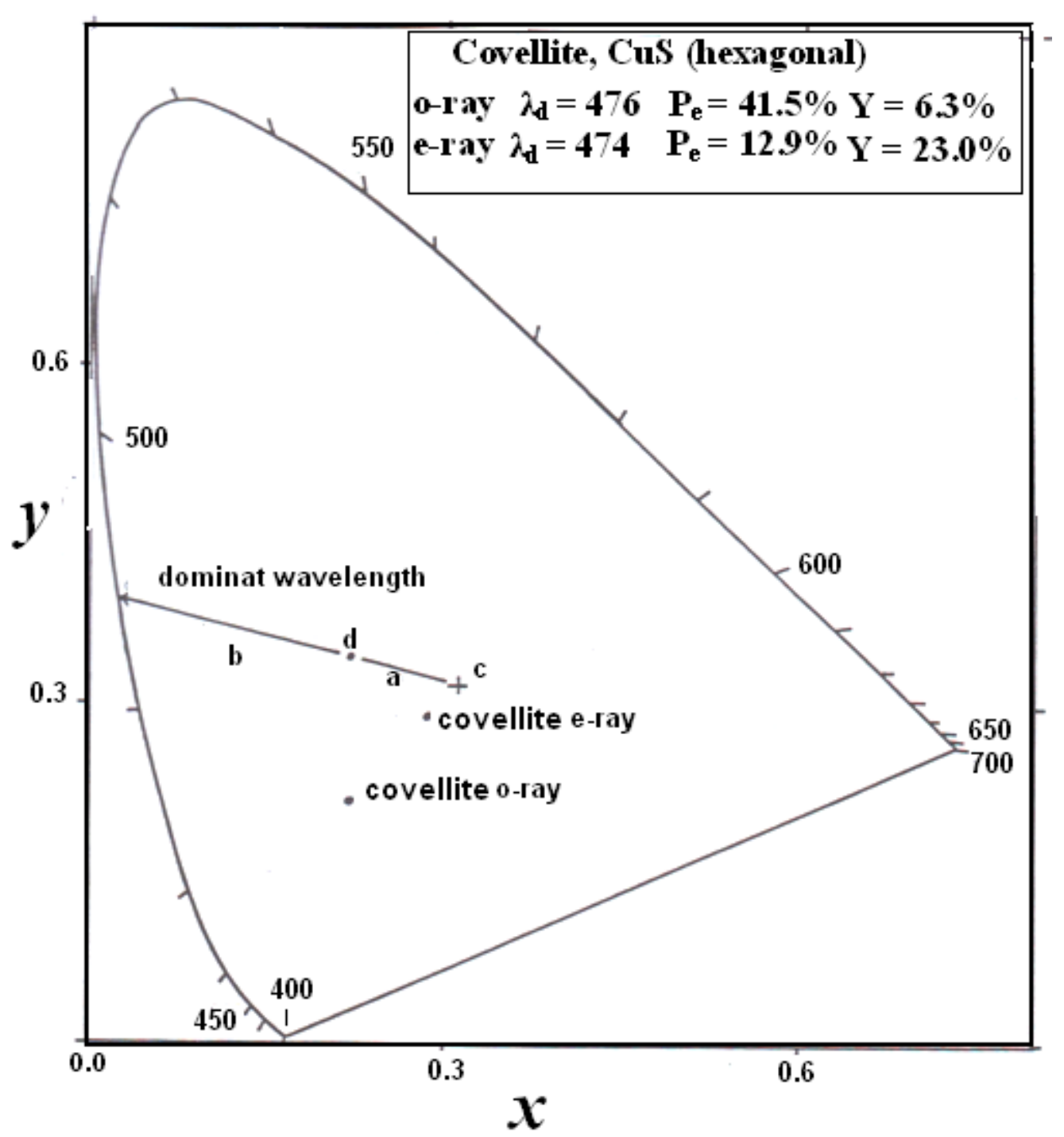

Fig. 3:The CIE (1931) Chromaticity Diagram (Judd, 1952). Derivation of Helmholtz Colour Coordinates $\lambda_{d}$ and $\mathrm{P}_{\mathrm{e}}$ for Mineral Plotted at Point (d) is as Follow:

$\lambda_{d}=495 \mathrm{~nm}$ (intersection of the line joining c-source and point $\mathrm{d}$ with spectral locus).

$$
\mathrm{P}_{\mathrm{e}}=\frac{100 a}{a+b}
$$




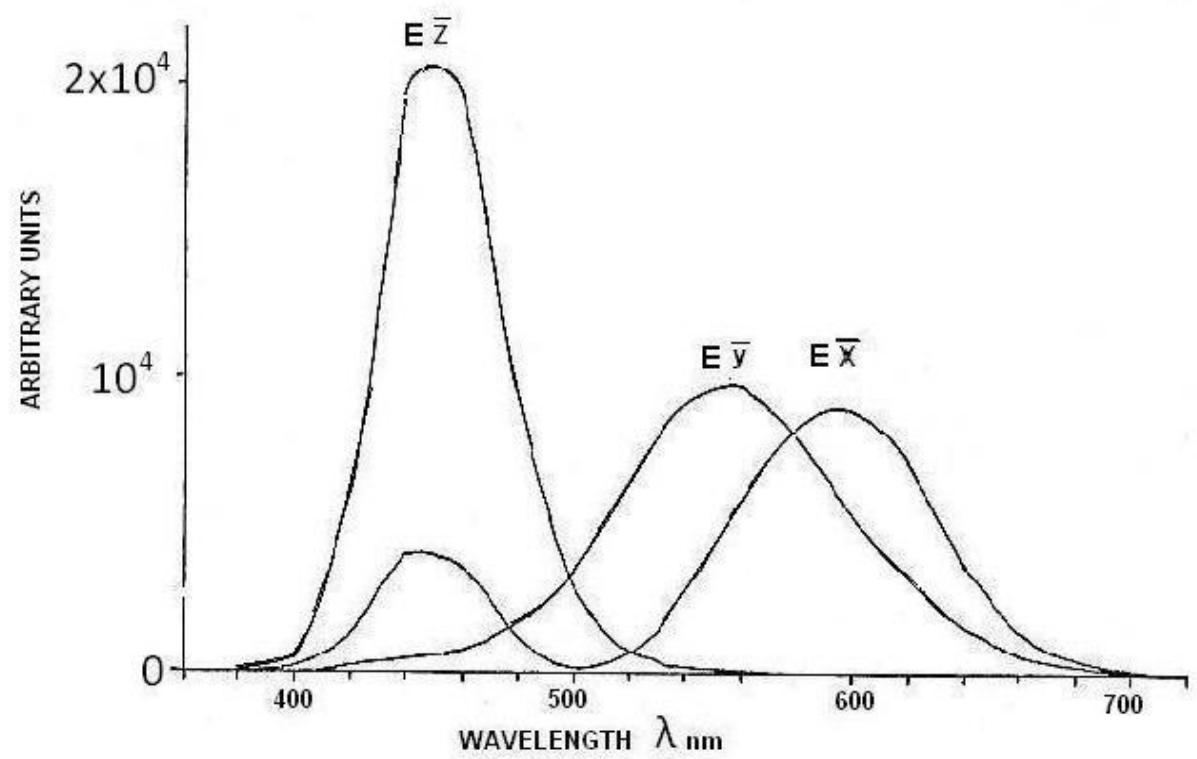

Fig. 4: Curves of $E \bar{x}, E \bar{y}$ and $E \bar{z}$ for $C I E$ standard sources $C$. These curves correspond to the required spectral sensitivity of the photometer system using each of the three filters when Csource colour values are required.

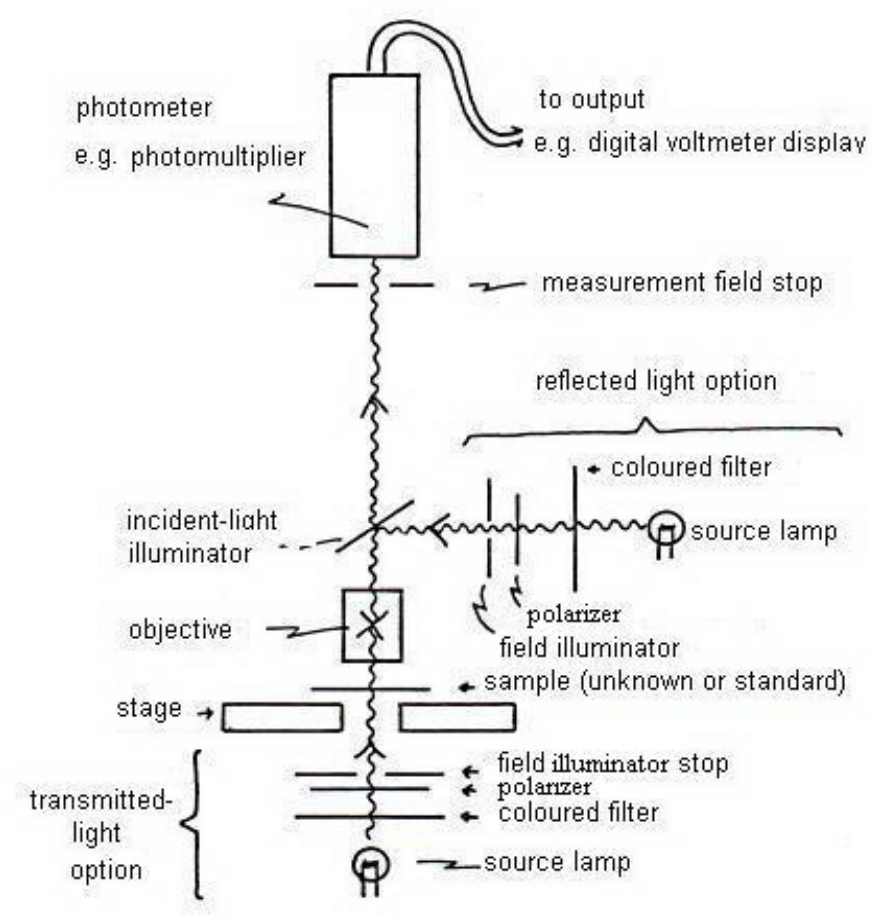

Fig. 5: Simplified Diagram of Essential Components of Micro-Photometer.

The bimodal nature of the red (x) curve complicates the design of the appropriate filter but the tristimulus values can be determined in two steps as will be explained below. The coloured filters provide a means of weighting the intensity of the source and the spectral sensitivity of the photometer. In this way 
the reflectance value obtained relative to the standard, gives the summation representing the tristimulus value.

The difficulty imposed by the bimodal nature of the red (X) curve can ideally be overcome by using two filters, one with a spectral transmission which gives a weighting corresponding to the peak beyond $500 \mathrm{~nm}$ near the red end of the spectrum (Fig. 1) and the second with a spectral transmission which gives a weighting corresponding to the smaller peak below $500 \mathrm{~nm}$ near the blue end of the spectrum. The two measurements may be combined in the computation of the $\mathrm{X}$ tristimulus values. However, the smaller peak near the blue end of the spectrum has a dominant wavelength and a range similar to the blue $(\mathrm{Z})$ curve, and it equals $16.7 \%$ of the $(\mathrm{Z})$ value based on calculation using the weighted ordinate method. This value must be added to the measured $(\mathrm{X})$ value to give the true $(\mathrm{X})$ value. The tristimulus values were therefore obtained for the c-source in the following way from the measured intensities (I):

\section{$\underline{\text { Using green filter }}$}

$$
Y_{\text {sample }}=\frac{I_{\text {sample }} \times Y_{\text {standard }}}{I_{\text {standard }}}
$$

$\underline{\text { Using blue filter }}$

$$
Z_{\text {sample }}=\frac{I_{\text {sample }} \times Z_{\text {standard }}}{I_{\text {standard }}}
$$

Using red filter

$$
X_{\text {sample }}=\frac{I_{\text {sample }} \times X_{\text {standard }}}{I_{\text {standard }}}+\frac{16.7 Z_{\text {sample }}}{100}
$$

Note that $X_{\text {standard }}$ is the value for the wavelengths above $500 \mathrm{~nm}$ only (in order to exclude the above mentioned smaller peak). Also, the results obtained are for the c-source, not the source actually used (for simplicity because the spectral reflectance curve is independent of the source of illuminant).

Colour values, like reflectance can be measured in any orientation of a grain of a cubic mineral but should only be measured in extinction orientations of grains of non-cubic minerals. Individual grains of non-cubic minerals have two colours corresponding to the two spectral reflectance curves. Minerals can have one or two or three principal colours, corresponding to the principal vibration directions, depending on whether they are cubic, uniaxial or of lower symmetry. The two principal colour values of the uniaxial mineral covellite are plotted in( Fig. 3) as an example; covellite displays a marked pleochroism in polished section and the colour values of the o-ray and e-ray are quite separate as might be expected. 
Once the $\mathrm{X}, \mathrm{Y}$ and $\mathrm{Z}$ values have been obtained, the chromaticity coordinates and luminance can be calculated and the colour plotted on the CIE (1931) diagram if required. By dividing the standard values $\mathrm{X}, \mathrm{Y}$ and $\mathrm{Z}$ by the summation given by:

$$
Y=\sum_{300}^{740} E_{c} \bar{y}
$$

It is possible to make the $\mathrm{Y}$ tristimulus value obtained for a mineral equate with the luminance value. This eliminates the simple calculation used in obtaining the luminance and means that the luminance is essentially measured directly.

In order to demonstrate the capability of using these filters for enhancement of mineral parageneses in ores, a photo image with bornite and chalcopyrite is selected (Plate1a). Applying ENVI V.4.6, an image processing software (at the Remote Sensing Center/Mosul University) used in remote sensing applications, it is possible to separate wavelengths corresponding to red, green and blue(RGB) colours from this image and select maximum band width values for each colour depending on maximum wavelength range values taken from spectrum of the filters used in this study (Fig. 1). Then the three maxima are composited giving the result presented in photo image (Plate 1b) that might obviously shows to some extent a better mineral paragenitic distinction compared to (Plate 1a). 
Plate 1: Photomicrograph of chalcopyrite exsolution growth in bornite under reflected PPL microscope.

(a) Before applying ENVI V. 4.6 image processing Software.

(b) After applying ENVI V. 4.6 image processing Software.
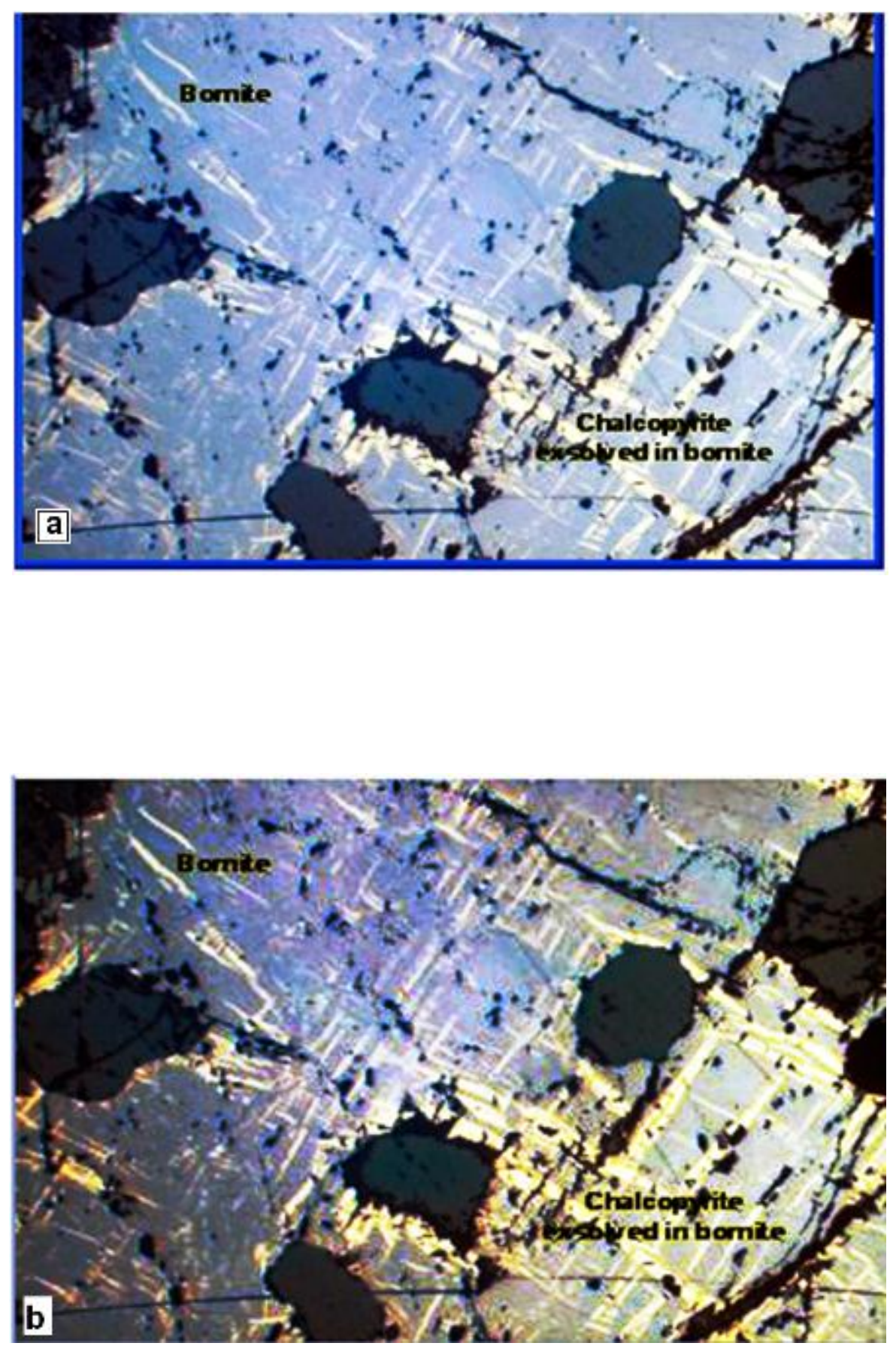


\section{DISCUSSION AND CONCLUSIONS}

It is possible to obtain "off the shelf" filters with spectral transmissions approximating to those required. Ultraviolet, infra-red and neutral density filters were used to protect the sensitive photomultiplier on the Vickers M74 micro photometer used in our prototype system. A SiC standard $(\mathrm{x}=0.307, \mathrm{y}=0.313$ and $\mathrm{Y}=20.35)$ was used with a Lanham specimen interchanging stage.

The colour values of eight representative opaque minerals obtained using filter method are compared with published values in Table (1). Results may be considered satisfactory where there is a matching of the colour values to within \pm 1 relative $\%$ (Fig. 6). Poor matching can be attributed to measuring errors, polishing effects, compositional variations and orientation effects as well as errors inherent in the technique. The low $\mathrm{x}$ and $\mathrm{y}$ values obtained for yellow and reddish minerals and the high values of $\mathrm{x}$ and $\mathrm{y}$ for the blue covellite o-ray may point to an incorrect weighting being provided by the $\mathrm{X}$ and $\mathrm{Z}$ filters at the red and blue extremities of the spectrum. The results presented can only be taken to indicate that the technique has promise as a simple means of determining quantitative colour values.

Theoretical considerations and preliminary results indicate that it should be possible to develop an inexpensive filter-photocell system suitable for colour measurements of ore minerals in reflected light. The method could also be applied to transmitted-light studies. Ore minerals would be identifiable by comparison of chromaticity coordinates $\mathrm{x}$ and $\mathrm{y}$ and luminance $\mathrm{Y} \%$ using tabulated or computerstored reference data. Identification is not the only potential use of this technique; it could also be used as an aid in the teaching of colour theory, for example to demonstrate optical phenomena such as pleochroism in minerals and how this may result from variations in luminance and/or chromaticity. The major disadvantage of the technique is that it gives only approximate colour values; this is because even if colour filters with the exact spectral transmission properties can be obtained, the spectral output from the bulb and the spectral sensitivity of photometer will inevitably vary with both short and long term use. It remains to be determined whether this invalidates the technique for the limited applications suggested here; it certainly implies that spectral reflectance measurements (the conventional method) will remain the best method of obtaining the standard colour data. 
Table 1: Comparison of quantitative colour values for a C-source obtained in the present study with reference values.

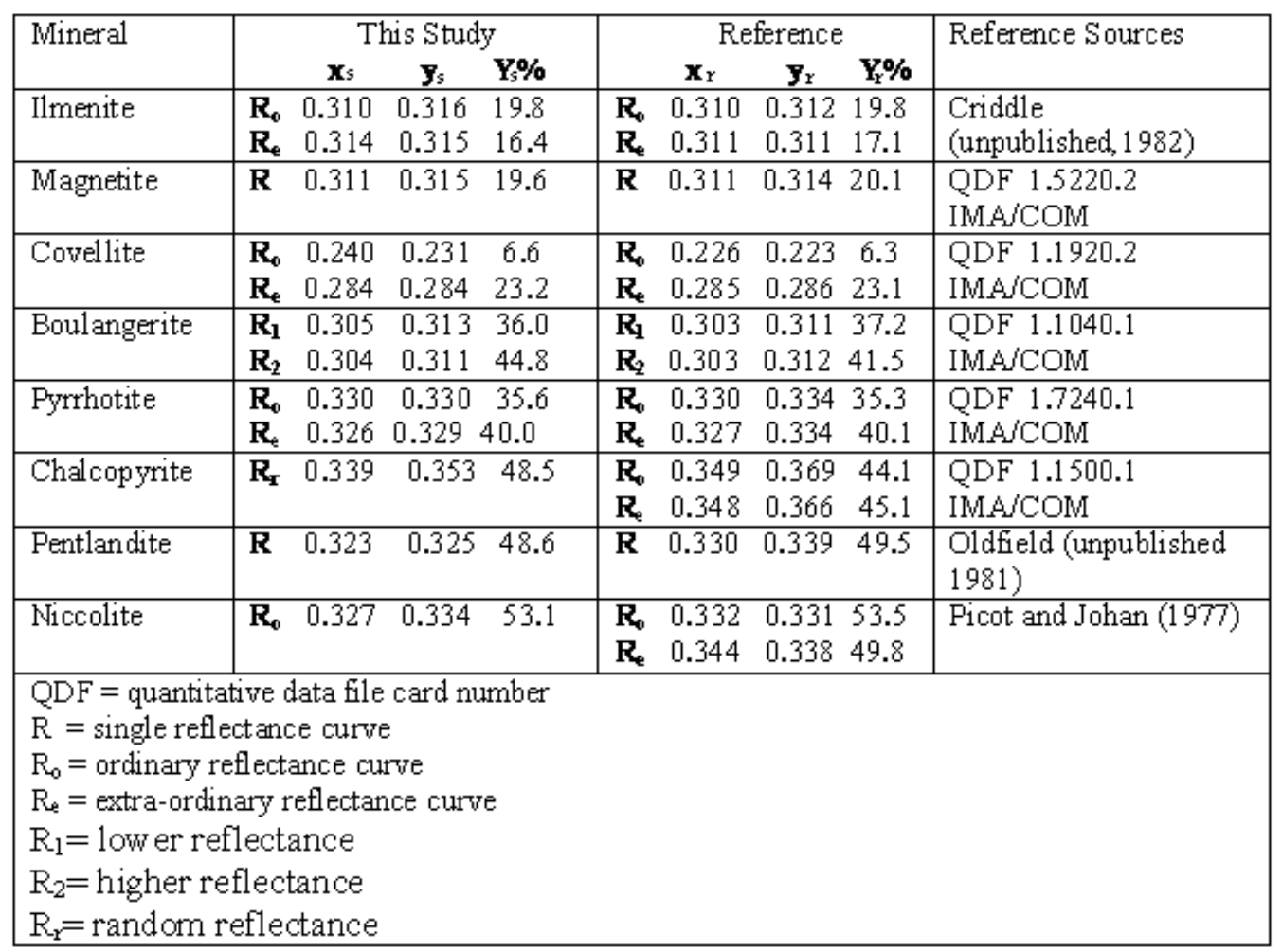

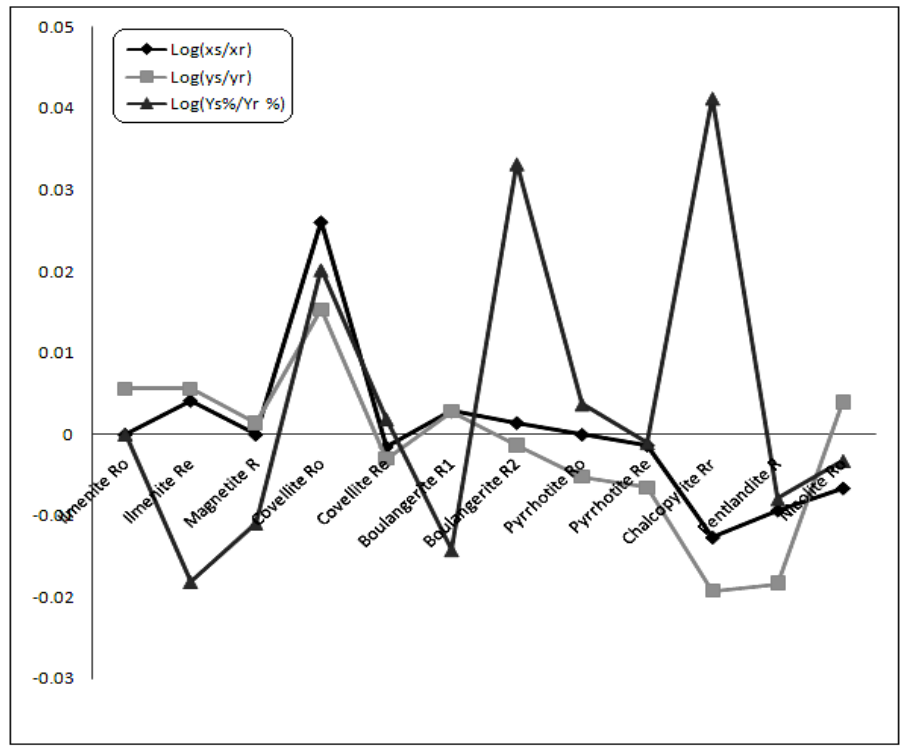

Fig. 6: Correlation Sketch Diagram (accuracy \%) between Obtained Colour Values of this Study $\left(\mathrm{x}_{\mathrm{s}}, \mathrm{y}_{\mathrm{s}}\right.$ and $\left.\mathrm{Y}_{\mathrm{s}} \%\right)$ and Corresponding Reference Values $\left(\mathrm{x}_{\mathrm{r}}, \mathrm{y}_{\mathrm{r}}\right.$ and $\left.\mathrm{Y}_{\mathrm{r}} \%\right)$. 


\section{REFERENCES}

Atkin, B. P.; and Harvey, P. K., 1979a. Nottingham Interactive System For opaque Mineral Identification: NISOMI. Inst. Mining Metal. Trans. Vol. 88, pp. B 24 - 27.

Atkin, B. P., and Harvey, P. K., 1979b. The use of quantitative Colour Values for Opaque- Mineral Identification. Can. Miner., Vol. 17, pp. 639 - 647.

Bowie, S. H. U. and Henry, N. F. M., 1964. Quantitative Measurements with the Reflecting Polarizing Mmicroscope. Inst. Mining Metal. Trans. Vol. 73, pp. $467-478$.

Bowie, S. H. U. and Simpson, P. R. 1978. The Bowie-Simpson System for the Microscopic Determination of ore Minerals. First Students Issue. Trans. Vol. 73, pp. 467 - 478.

Cervelle, B., Levy, C. and Caye, R., 1971. Dosage Rapide Du Magnesium Dans les Ilmenites Par Micro Reflectometrie. Mineral. Deposita, Vol. 6, No.1, pp. 34 - 40.

Criddle, A.J., 1980. Editorial Policy for the Second Issue of the IMA/COM Quantitative Data File. Can. Mineral., Vol. 18, pp. 553 - 558.

Criddle, A. J., 1998. Ore Microscopy and Photometry (1890-1998). In Mmodern Approaches to Ore and Environmental Mineralogy (Carbi, L. J. and Vaughan, D. J., editors). Short Course Series, 27, Mineralogical Association of Canada, Ottawa.

Criddle, A. J., and Stanley, C. J., 1993. Quantitative Data File for Ore Minerals, $3^{\text {rd }}$ ed., Chapman and Hall, London, UK, 635p.

Galopin, R., and Henry, N. F. M., 1972. Microscopic Study of Opaque Minerals. W. Heffer and Sons Ltd., Cambridge, 322 p.

Gomes, O. D. M, Sidnei, P. and Julio, C. A. I, 2010. A simple Methodology for Identifying Hematite Grains under Polarized Reflected light Microscopy. IWSSIP-17th International Conference on System, Signal, and Image Processing. pp. $428-431$.

Gribble, C. D. and Hall, A. J., 1992. Optical Mineralogy: Principles and Practice. 2nd edition UCL Press. London. 303p

Hardy, A. C., 1936. Handbook of Colorimetry. Cambridge, Massachusetts: The Technology Press, MII, 87p.

Henry, N.F.M., ed. 1977. Commission on Ore Microscopy, IMA/COM Quantitative Data File, 1st issue, International Mineralogical Association, McCrone Research Associates, London, UK.

Henry, N. F. M., 1980. IMA/COM Report on Symbols and Definitions. Can Mineral., Vol. 18, pp. 549 - 551.John Betts-Fine Minerals. Reflectance in Minerals. http:// webmineral.Com/help/reflectivity.

Judd, D. B., 1952. Colour in Business, Sciences and Industry. New York: John wiley.

Judd, D. B., and Wyszecki, G., 1963. Colour in Business, Science and Iindustry, $2^{\text {nd }}$ ed., J. Wiley and Sons Inc., New York, 500 p. 
Kruse, F. A, 1996. Identification and Mapping of Minerals in Drill Core using Hyperspectral Image Analysis of Infrared Reflectance Spectra. International Journal of Remote Sensing, Vol. 17, Issue 9, pp.1623-1632.

Leow, J. H., 1966. Reflectivity Measurements of Molybdenite. Econ. Geol., Vol. 61, pp. 598 - 612.

Piller, H., 1966. Colour Measurements in Ore-Microscopy. Mineral. Deposita, Vol. 1, pp. 175-192.

Piller, H., 1977. Microscope Photometry. Springer-Verlag, Berlin.

Picot, P. and Johan, Z., 1977. Atlas Des Mineraux Metalliques., Mem. Bur. Rech. Geol. Minieres, Vol. 90, 406 p.

Pirard, E., 2004. Multispectral Imaging of Ore Minerals in Optical Microscopy. Min. Mag., Vol. 68, No. 2, pp. 323 - 333.

Pirard, E., Bernhardt, H. J, Catalina, J. C, Brea, C., Segundo, F. and Castroviejo, R., 2008. From Spectrophotometry to Multispectral Imaging of Ore Minerals in Visible and Near Infrared (VNIR) Microscopy. Nineth International Congress for Applied Mineralogy, Brisbane, QLD, 8-10 September. pp.1 - 6.

Pirard, E. and Lebichot, S., 2011. Automated Recognition of Hematite Grains under Polarized Reflected light Microscopy through Image Analysis. Minerals Engineering, in Press.

Pirard, E., Lebichot, S. and krier, W., 2007. Particle Texture Analysis using Polarized light Imaging and Grey level Intercepts. Int. J. Miner. Process, Vol. 84, pp. 299 - 309.

Pirard, E., Lebrun, V. and Nivart, J. F., 1999. Optimal Acquisition of Video Images in Reflected light Microscopy. European Microscopy and Analysis, Vol. 60, pp.9 - 11.

Shippert, p, 2008. Introduction to Hyperspectral Image Analysis. http:// Satjournal. Tcom Ohiou edu/pdf/Shippert pdf.

Uytenbogaardt, W. and Burke, E. A. J., 1971.Tables for Microscopic Identification of Ore Minerals. $2^{\text {nd }}$ ed., Elsevier, Amsterdam. 